\title{
PROGRAMA FUNDECAM EMPREENDEDOR: O PERFIL DO EMPREENDEDOR DE PEQUENOS NEGÓCIOS
}

\author{
Fundecam Empreendedor Program: Profile of the Small Business Entrepreneur
}

\begin{abstract}
Resumo: 0 presente estudo teve como objetivos mapear e diagnosticar os empreendedores beneficiados pelo programa de microcrédito do Fundo de Desenvolvimento de Campos (Fundecam), desenvolvido pela Prefeitura de Campos dos Goytacazes, estado do Rio de Janeiro, e analisar o impacto do microcrédito em seus empreendimentos. Para alcançar os resultados, foram aplicados questionários a tomadores de microcrédito, que permitiram analisar 0 perfil dos tomadores de créditos, levando em consideração os aspectos socioeconômicos, os níveis de conhecimento e adesão com o programa e as dificuldades enfrentadas no processo de financiamento. Pelos resultados da pesquisa, pôde-se perceber o bom desempenho do Programa Fundecam Empreendedor, impactando os microempreendedores locais e contribuindo para o desenvolvimento local endógeno.
\end{abstract}

Palavras-Chave: Microcrédito. Desenvolvimento Econômico. Ações empreendedoras.

Alzeleni Pio da Silva Tavares Correâ, Waidson Bitão Suett, Rodrigo Anido Lira, Mariana Freitas de Abreu

\begin{abstract}
The objectives of this study were to map and identify the entrepreneurs who have been benefited by the Development Fund (Fundecam, abbreviation in Portuguese) microcredit program of Campos dos Goytacazes, developed by the Campos dos Goytacazes city government, state of Rio de Janeiro, Brazil, and to examine the impact of microcredit on their enterprises. Results were obtained by applying questionnaires to microcredit borrowers, which made it possible to analyze the profile of the borrowers, considering the socioeconomic aspects, the levels of education, adhesion to the program, and the difficulties faced in the financing process. According to the results of the research, it was noted the good performance of the Fundecam Empreendedor Program, impacting local microentrepreneurs and contributing to endogenous local development.
\end{abstract}

Keywords: Microcredit. Economic development. Entrepreneurial actions. 


\section{Introdução}

Cada vez mais a globalização imputa transformações, sendo elas principalmente no cenário econômico das regiões, o que contribui para um aumento das desigualdades regionais e da competitividade. Isso posto, novas maneiras de se pensar o desenvolvimento das organizações e das localidades são necessárias.

0 desenvolvimento econômico pode ser definido como o aumento sustentado da produtividade ou da renda per capita, bem como o processo de acumulação de capital e fatores de produção (BRESSER-PEREIRA, 2006).

Segundo Bresser-Pereira (2006), os melhores resultados do desenvolvimento acontecem em países que adotaram o sistema capitalista por sua maior dinâmica competitiva, pois a sobrevivência das empresas depende exclusivamente da acumulação de capital.

As taxas de desenvolvimento econômico são diferentes entre países, assim como entre regiões, estados e municípios do território nacional. Nota-se que as condições de desenvolvimento econômico consideradas adequadas dependem da capacidade de cada localidade (região, município, estado ou país) de gerenciar sua economia e mercado, para promover o desenvolvimento.

0 atual cenário nacional e regional é de inúmeras incertezas econômicas e políticas. De acordo com Barboza e Zilberman (2018), a condição atual possui efeitos negativos sobre a atividade econômica no Brasil, destacando-se a queda de investimento de capital privado e uma consequente redução dos postos de trabalho.
No que concerne à taxa de desemprego no Brasil em 2020, nota-se um aumento de 12,6\% no trimestre encerrado em abril de 2020, segundo dados da Pesquisa Nacional por Amostra de Domicílios (PNAD) e do Instituto Brasileiro de Geografia e Estatística (IBGE). A taxa é superior aos $11,2 \%$ do trimestre encerrado em janeiro de 2020. 0 número de empregados com carteira assinada no setor privado caiu $1,7 \%$ (-572 mil pessoas) frente ao trimestre móvel anterior e ficou estável ante o mesmo trimestre de 2019 (ABDALA, 2020).

Neste contexto de desemprego e desigualdades, tem-se o desenvolvimento endógeno, teoria que busca corrigir as desigualdades regionais com uso de ferramentas políticas. De acordo com essa teoria, a sociedade é capaz de controlar e direcionar o seu próprio desenvolvimento regional, forçando-o a adaptar-se à disponibilidade dos fatores produtivos locais e ao seu potencial endógeno.

0 desenvolvimento endógeno possui a capacidade de criar centros produtivos e solucionar os problemas de desequilíbrio, permitindo a identificação dos principais fatores de produção local, como: os capitais humanos e sociais, o conhecimento, a pesquisa e a informação na própria localidade.

Segundo Barone et al. (2002), o microcrédito é uma ferramenta importante para auxiliar o desenvolvimento endógeno local através da geração de renda, por meio do fomento de microempreendedores.

Entende-se microcrédito como a concessão de empréstimos de baixo valor a pequenos empreendedores informais e microempresas, que normalmente não possuem ou apresentam dificuldade de acesso formal ao sistema financeiro tradicional.

\section{Os seus sonhos não podem esperar}


0 município de Campos dos Goytacazes, interior do estado do Rio de Janeiro, possui o programa de microcrédito do Fundecam Empreendedor, ligado ao Fundo de Desenvolvimento de Campos (Fundecam). Através do programa de microcrédito, é possível disponibilizar capital para que os empreendedores coloquem em funcionamento suas ideias de negócio ou ampliem seus ativos.

Em 2017, o Fundecam Empreendedor fechou mais de 200 contratos, totalizando meio milhão em concessão de financiamento para microempreendedores, mantendo mais de 320 postos de trabalho no município. Neste contexto, justifica-se o presente trabalho pela importância de conhecer os empreendedores agentes deste processo de desenvolvimento econômico local.

0 presente trabalho estrutura-se em sete seções. $\mathrm{Na}$ seção 2, expõe-se uma definição teórica acerca do desenvolvimento endógeno. A seção 3 apresenta 0 conceito de microcrédito e apresenta o Programa Fundecam Empreendedor. Na seção 4, mostra-se a metodologia de pesquisa utilizada. Na seção 5 , são apresentados os resultados da pesquisa e, por fim, na seção 6, são apresentadas as considerações finais.

\section{Desenvolvimento regional endógeno}

Pensar em desenvolvimento é entender a dinâmica da formação produtiva crescente. Nos modelos econômicos clássicos, a produção é o resultado da ação do trabalho e do capital, sendo seu excedente essencial ao desenvolvimento. Contudo, é importante entender também o desenvolvimento tendo em conta a possibilidade de endogenizar as variáveis exógenas, de maneira que estas possam gerar rendimentos crescentes para uma determinada localidade.

Para Romer (1994), o crescimento da economia é uma consequência da endogenia do sistema econômico, pois o crescimento não é alcançado somente a partir das variáveis externas.

Segundo Barquero (2001), o desenvolvimento da economia advém do emprego do potencial e do excedente gerado localmente. Ainda segundo o autor, existe uma "tendência ao estado estacionário", sendo necessário para o crescimento e desenvolvimento econômico fomentar a economia de diversidade nas cidades e a economia de aglomeração.

Neste contexto apontado pelos autores, observa-se a importância do desenvolvimento a partir de fatores endógenos regionais. Para Amaral Filho (1996, p. 37-38), o desenvolvimento regional endógeno pode ser definido como:

\begin{abstract}
(...) um processo interno de ampliação contínua da capacidade de agregação de valor sobre a produção, bem como da capacidade de absorção da região, cujo desdobramento é a retenção do excedente econômico gerado na economia local e/ou a atração de excedentes provenientes de outras regiões. Esse processo tem como resultado a ampliação do emprego, do produto e da renda do local ou da região, em um modelo de desenvolvimento regional definido.
\end{abstract}

De acordo com Souza Filho (1999), a prática de uma comunidade comandar e coordenar o seu próprio desenvolvimento regional, proporcionando a mudança de suas condições disponíveis em seu território e a sua capacidade endógena, caracteriza a figura do desenvolvimento intitulado endógeno. Percebem-se dois enfoques do desenvolvimento regional endógeno: o primeiro econômico, no qual a sociedade organizacional regional dispõe de seu conhecimento para coordenar, de modo a promover o aumento da capacidade produtiva da região; o segundo é o sociocultural, em que os preceitos e as sociedades locais atuam como alicerces para o desenvolvimento da região.

Segundo Braga (2002, p. 24), o desenvolvimento endógeno é componente principal para a ascensão do local. Ele atua como protagonista no incremento econômico em uma economia competitiva, promovendo a disputa entre as microrregiões em vez de disputa entre as organizações empresariais, permitindo que o local seja erguido como espaço favorável à cidadania, inclusão social e solidariedade. 
A Figura 1 apresenta os dois enfoques do desenvolvimento intitulado endógeno.

Schumpeter (1982) destacou a importância do empreendedor na atividade econômica; para ele. a mudança econômica é iniciada pelo produtor, e este deve ser capaz de utilizar sua intuição quando não se tem certeza dos resultados. 0 autor também destaca a importância do crédito para o crescimento econômico. Segundo Schumpeter, o empreendedor precisa ter acesso ao crédito, pois, a partir dele, é possível produzir e executar novas combinações de fatores de produ-

Figura 1: enfoque do desenvolvimento regional endógeno.

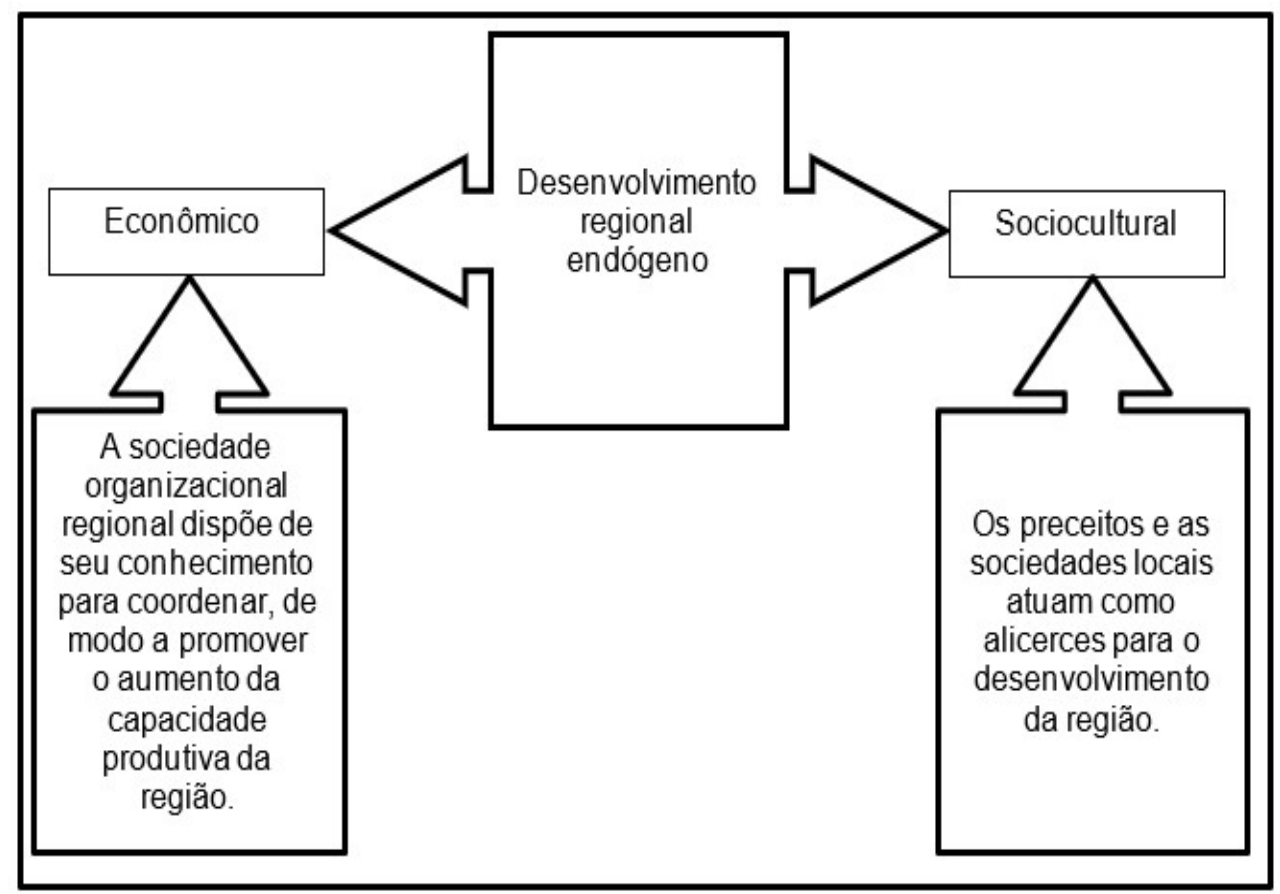

Fonte: adaptado de Barqueiro (2001).

INSCREVA-SE

\section{Os seus sonhos} não podem esperar

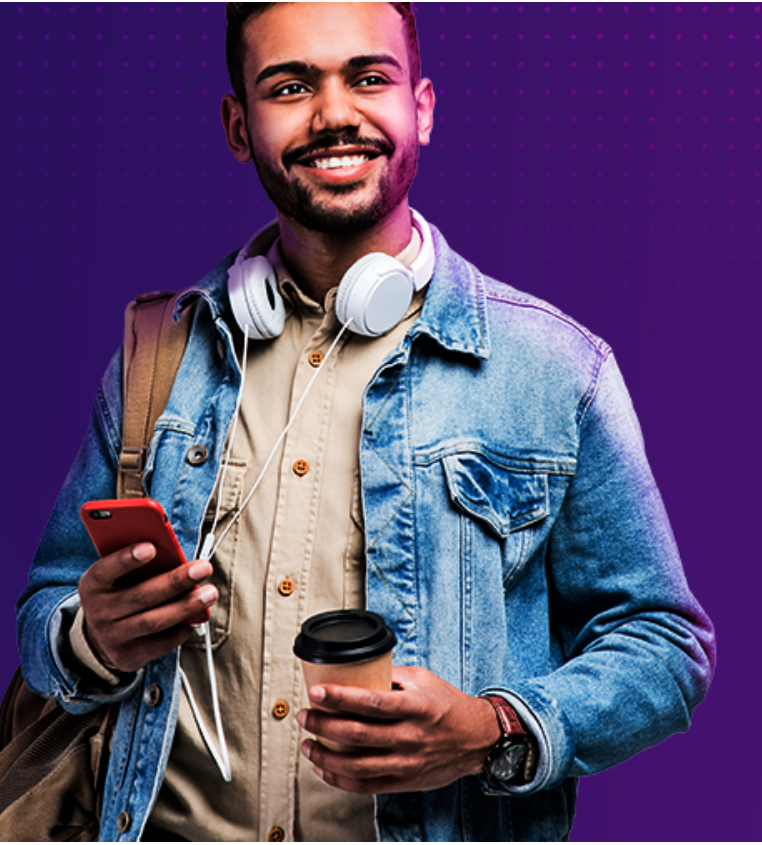


ção, evitando-se o estágio estacionário da economia.

\section{Programa de microcrédito}

A ideia de pequenos empréstimos para ajudar pequenos comerciantes começou em Bangladesh por volta da década de 1970. Lá, o professor Muhammad Yunus concedia pequenos empréstimos aos aldeões da região de Jobra como parte de um projeto. Com o eventual sucesso da sua iniciativa, o projeto tomou maiores proporções, sendo hoje uma medida de fomento à economia, conhecida e, por muitas vezes, praticada no mundo todo. Essa política também esteve presente no Brasil, com a participação do poder público com suas instituições e da iniciativa privada. No caso do poder público, essa política é observada em todas as esferas de atuação, desde a federal até a municipal. Tanto na privada como na pública, há suporte para os empreendedores, como meio de capacitação e forma de diminuir a inadimplência dos investimentos por falência (YUNUS; JOLIS, 2006).

A política de concessão de microcrédito a pequenas taxas de juros não visa o retorno dos investimentos e os eventuais juros como base para gerar uma fonte de renda para o investidor. Isso se dá pelo fato de que essa política visa estimular o empreendedorismo local. Por isso, as instituições públicas são uma das maiores aderentes dessa política de microcrédito, por ser também uma das mais beneficiadas com o estímulo do empreendedorismo.

0 microcrédito é considerado um estímulo ao empreendedorismo, porque, na visão do empreendedor, é necessário que a possibilidade de retorno de seus investimentos, de seu capital próprio e da dívida que pretende contrair, seja maior do que a de falência. Seu valor é proporcional ao tamanho e à capacidade financeira do negócio, e, com seus juros menores, a intenção é a de diminuir a chance de falência, ou mesmo minimizá-la. Outra característica importante presente nessa política é a de que muitas vezes a instituição que investe também oferta algum tipo de serviço que ajude na capacitação do empreendedor, não só para que ele seja capaz de melhorar suas práticas, mas para que haja maior capacidade intelectual para que 0 investimento dê certo e não haja inadimplência quando o devedor não conseguir quitar suas dívidas dentro do tempo proposto pelo contrato do financiamento (SEBRAE, 2007).

Com a baixa perspectiva de um emprego formal, muitos trabalhadores acabam iniciando um negócio próprio. Entretanto, além do despreparo empresarial e empreendedor, estes indivíduos enfrentam dificuldades para iniciar e/ou conduzir suas atividades, devido à falta de crédito.

0 microcrédito se apresenta como uma importante ferramenta no combate à pobreza no mundo. No Brasil, várias organizações dedicam-se a conceder pequenos créditos a microempreendedores.

De acordo com Lessa (2001), no Brasil, o acesso ao crédito para os micro e pequeno empresários, sobretudo aqueles que estão iniciando seus negócios, continua sendo um problema. Mesmo que tenha uma ideia promissora, o empreendedor não consegue crédito bancário com facilidade.

Segundo Tomelin (2003), o microcrédito é a concessão de empréstimos de baixo valor a pequenos empreendedores informais e a microempresas sem acesso ao sistema financeiro tradicional, principalmente por não terem como oferecer garantias reais.

0 prazo para liberação de crédito costuma ser rápido, porque, dessa forma, permite que o cliente aproveite a oportunidade do negócio. Nesse tipo de financiamento, ocorre a visita de um agente de crédito ao empreendimento no qual os recursos serão aplicados, a fim de que se acompanhe o desenvolvimento do negócio. É também nesta etapa que o empreendedor costuma receber orientações quanto às práticas básicas para uma boa administração dos recursos do negócio.

Segundo Soares (2008), a Lei $n^{0}$ 11.110/2005 veio consolidar o conceito de microcrédito ao apresentar - Microcrédito Produtivo Orientado (MPO) como um crédito concedido para o atendimento às necessidades financeiras de pessoas físicas e jurídicas, empreendedoras de atividades produtivas de pequeno porte, que utiliza metodologia baseada no relacionamento direto com os empreendedores no local onde é executada a atividade econômica. 


\section{Programa Fundecam Empreendedor}

Com o objetivo de contribuir para o desenvolvimento econômico e social, fomentando os empreendimentos produtivos, o fortalecimento dos negócios existentes e a introdução e formalização de novos empreendimentos, com acompanhamento, capacitação e acesso a crédito orientado, e, também, desenvolvendo ações específicas no âmbito da economia popular e solidária e nos movimentos de inclusão social, foi criada a Lei Ordinária $n^{0}$. 8142/2009 no município de Campos dos Goytacazes. A partir dessa lei, houve a criação de linha especial de financiamento, direcionada para a implantação do microcrédito no município.

Utilizando os fundos próprios do município e respeitando a lei do microcrédito, a Fundecam apresenta o Programa Municipal de Microcrédito. 0 referido programa é constituído por quatro linhas de financiamento, sendo uma delas o Fundecam Empreendedor. No Fundecam Empreendedor, o público almejado são microempreendedores que estejam atuando há pelo menos seis meses, sem pendências no SERASA/SPC e com perspectiva de faturamento anual de até $R \$ 240$ mil.

Esta modalidade apresenta duas categorias: Capital de Giro e Investimento Fixo. A primeira é destinada à compra de mercadorias, com crédito de até R\$ 2 mil a serem pagos em seis parcelas. 0 Investimento Fixo, por sua vez, deve ser utilizado para a aquisição de equipamentos ou reforma, podendo ser concedidos até R\$ 3 mil, para quitação em nove parcelas. Caso haja renovação, as categorias podem recorrer a mais 50\% de cada valor, e têm o prazo de pagamento estendido.

No Fundecam Empreendedor, os juros são de 0,17\% ao mês, significando um índice anual de apenas $2 \%$. 0 programa também possui um trabalho de consultoria aos microempreendedores tomadores de empréstimo. Desta forma, são ampliadas as possibilidades de prosperidade e geração de empregos.

\section{Metodologia de pesquisa}

A fim de atender aos propósitos deste artigo, a metodologia consiste no embasamento do método qualitativo a partir de pesquisas bibliográficas, pois parte da análise do que já foi divulgado sobre o tema no formato de livros, artigos científcos, teses, dissertações e legislação vigente sobre os temas de empreendedorismo e microcrédito e do método quantitativo por meio do questionário aplicado a uma amostra de 100 tomadores de microcrédito.

Com o objetivo de responder à questão do problema, foi desenvolvido e aplicado um questionário aos tomadores de microcrédito na cidade de Campos dos Goytacazes, no período de fevereiro de 2019 a abril de 2019, com questões discursivas e de múltipla escolha, aplicado aos beneficiários do programa Fundecam Empreendedor, contendo informações gerais do microempreendedor e informações para definição do perfil sociodemográfico. Segundo Oliveira (2003, p. 71), "0 questionário constitui-se de uma série ordenada de perguntas relacionadas a um tema central, que são respondidas sem a presença do entrevistador."

Os questionários, em formato eletrônico, foram entregues via e-mail para acesso por link, gerado por meio de uma ferramenta gratuita oferecida pelo Google: o Google Forms. Para a realização da pesquisa, desde os testes até a aplicação prática, o questionário ficou disponível para preenchimento no site do Google Forms no endereço https://forms.gle/nwcNhr7qJyNKzcG86.

Antes de ser iniciada a aplicação, foi realizado um pré-teste com o mesmo conteúdo a ser respondido pelos tomadores de crédito, escolhidos aleatoriamente, para que o formulário pudesse ser analisado por outra ótica, sendo possível corrigir prováveis erros antes do início das pesquisas de campo.

0 questionário foi aplicado no período de fevereiro de 2019 a abril de 2019. Por fim, para interpretar os dados, utilizou-

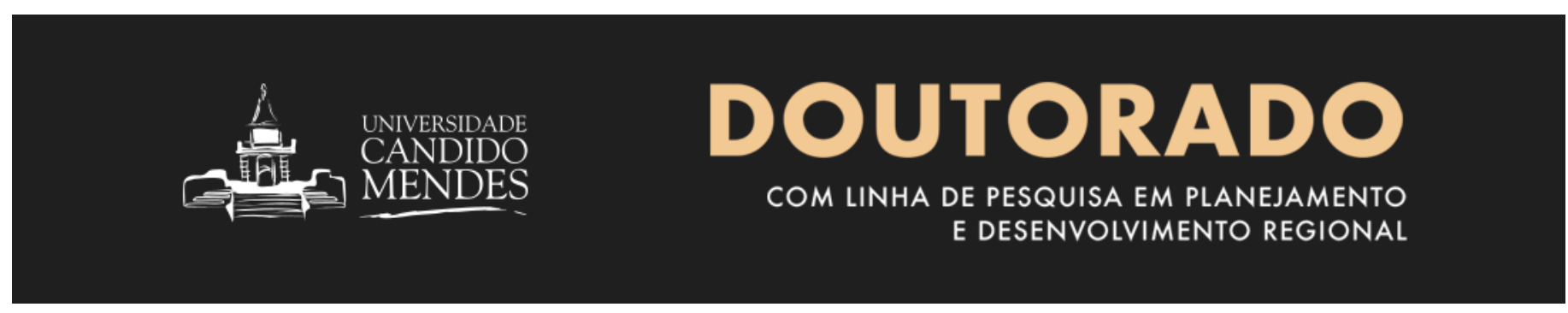


-se a análise dos dados quantitativos obtidos a partir da tabulação dos questionários no software Microsoft Office Excel.

\section{Resultados}

Para que a pesquisa de campo fosse realizada, foram entrevistados 100 microempreendedores que tomaram crédito pelo programa Fundecam Empreendedor no ano de 2018. Os questionários foram aplicados do dia 12 de fevereiro de 2019 ao dia $1^{0}$ de abril de 2019.

O Gráfıco 1 apresenta a frequência das modalidades de financiamento para Capital de Giro, investimento Fixo ou ambos:
Do total de credores, quase metade optou pela modalidade de Capital de Giro, um recurso de rápida renovação, com as principais finalidades de realizar investimentos em estoque e financiar melhorias para 0 atendimento aos clientes.

O Investimento Fixo foi a segunda opção mais requisitada, sendo apontado como solução para 32,3\% dos tomadores de crédito. Essa modalidade de empréstimo, por sua vez, objetiva o bom funcionamento do negócio através da aquisição de equipamentos e ferramentas necessárias.

Na modalidade de Investimento Misto, pelo qual o credor tem acesso ao somatório de valores do Capital de Giro e do Investimento Fixo, houve procura de 19,2\% dos microempreendedores contatados.

Gráfıco 1: distribuição das modalidades de financiamento.

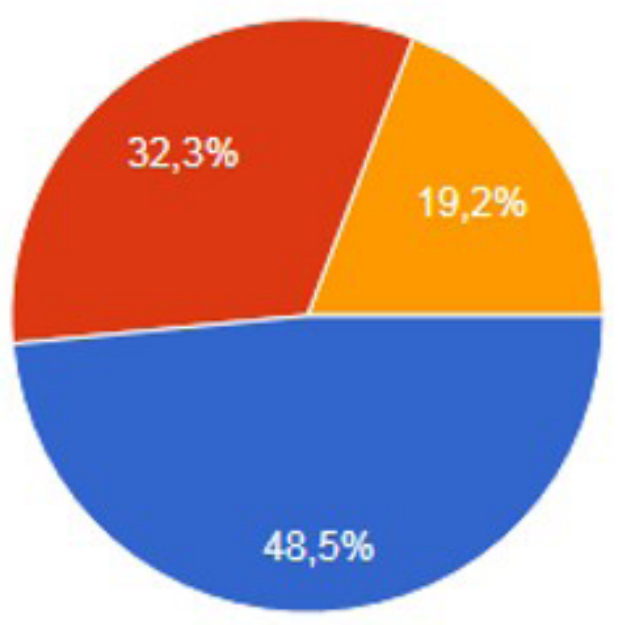

Capital de Giro

Investimento Fixo

Misto

Fonte: dados da pesquisa (2019).

MEST RA D 0

PESQUISA OPERACIONAL E INTELIGÊNCIA COMPUTACIONAL LINHA DE PESQUISA EM SAÚDE 
0 Gráfico 2 apresenta a distribuição da faixa de valores de empréstimos concedidos pela Fundecam:

Gráfıco 2: distribuição da faixa de valores dos empréstimos.

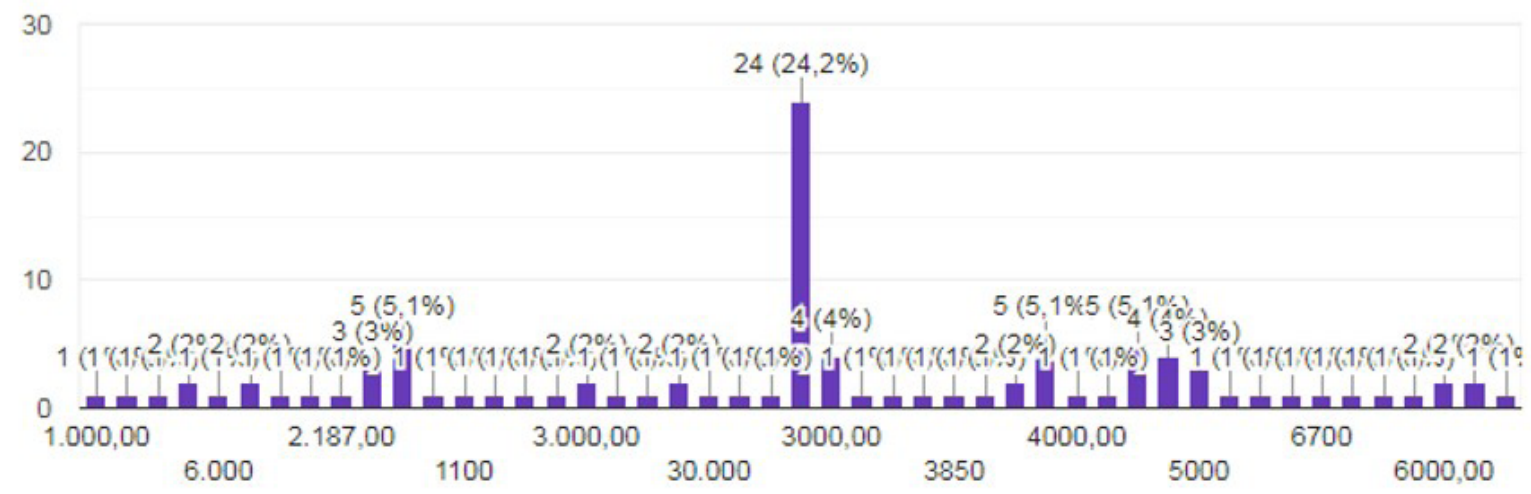

Fonte: dados da pesquisa (2019).

\section{DOUTORADO COM LINHA DE PESQUISA EM INSTRUMENTOS DE POLÍTICAS PÚBLICAS}

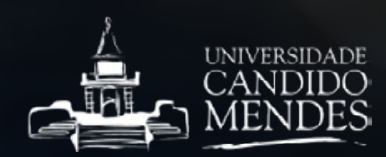


Como exposto anteriormente, os valores de financiamento das linhas de crédito são disponibilizados da seguinte maneira: até $R \$ 2.000,00$ para Capital de Giro; $R \$ 3.000,00$ para Investimento Fixo; e R\$ 5000,00 para Investimento Misto no primeiro empréstimo com maior concentração na concessão de crédito com o montante de $R \$ 3.000,00$.

Não é possível observar um padrão claro de recursos, devido ao vasto leque de possibilidades de valores a serem tomados pelos empreendedores, porém a análise da moda evidencia a opção de quase $1 / 4$ dos empresários, no valor de R\$ 3.000,00.

Os empréstimos são concedidos com variados prazos para pagamento, de acordo com as necessidades do tomador; no entanto, grande parte dessa variação ocorre no intervalo de 6 a 12 meses, adotados por $92 \%$ dos entrevistados. A maior parte dos clientes do Fundecam Empreendedor, nas três modalidades de concessão, estavam entre o primeiro e o segundo empréstimo no período de duração das entrevistas.
No que tange à formalização dos microempreendedores, por meio da pesquisa de campo, pode-se notar que mais de $70 \%$ dos utilizadores do Fundecam Empreendedor possuem o cadastro de pessoa jurídica. Entre essa parcela, $65,2 \%$ dos indivíduos possuem CNPJ há mais de dois anos; $23,6 \%$ possuem de 1 a 2 anos; $6,9 \%$ possuem de 6 a 11 meses; e apenas $4,2 \%$ dos tomadores de crédito se cadastraram há menos de seis meses.

Entre os nãos cadastrados, que somam $27,3 \%$ do total de entrevistados, mais da metade aspira à formalização. 0 município de Campos dos Goytacazes apresenta forte representação do comércio e serviços em sua economia. Tal situação pode ser evidenciada na distribuição de empréstimos por ramos de atividade no Gráfico 3:

Gráfico 3: distribuição de empréstimos por ramos de atividade.

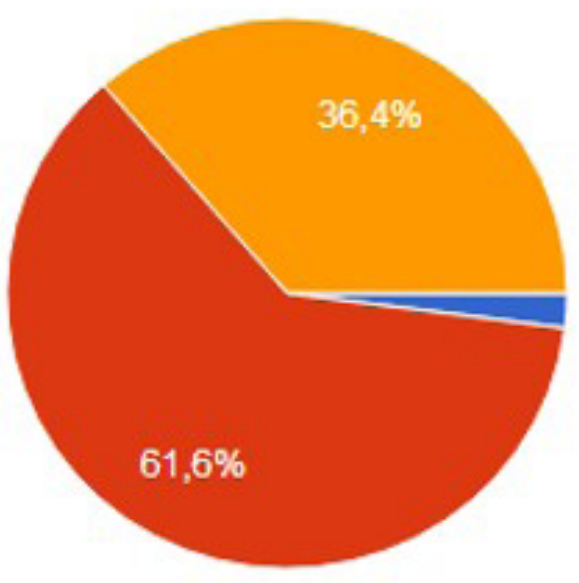

\author{
Indústria \\ Comércio \\ Serviços
}

Fonte: Dados da pesquisa (2019).

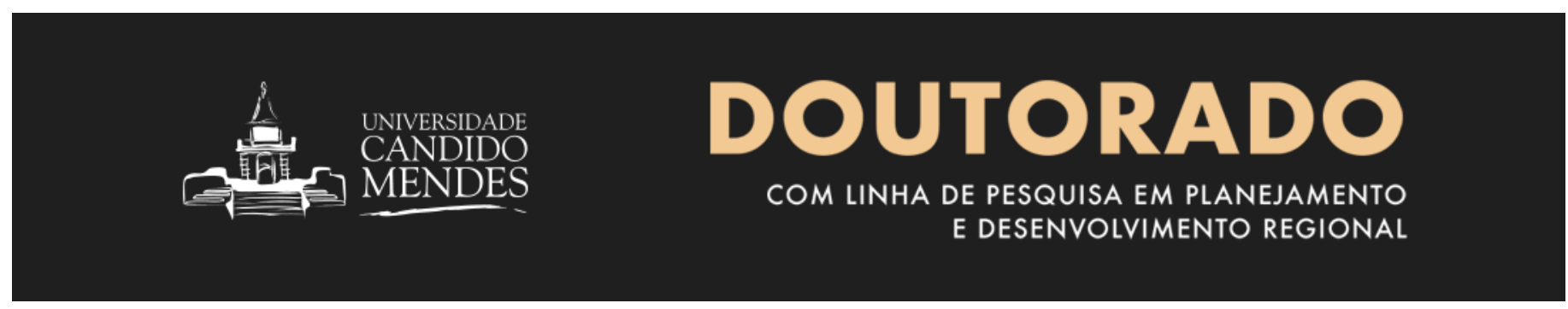


A maior parte dos empresários, $61,6 \%$, trabalha no setor de comércio, sendo seguido pelo setor de serviços, com $36,4 \%$. A indústria possui pouca representatividade entre os microempreendedores financiados através do Fundecam Empreendedor, visto que estes somam apenas 2\% do total.
Esses pequenos empreendimentos, assessorados pelo Fundecam Empreendedor, possuem proprietários que assumem inúmeras funções no negócio.

A distribuição do perfil dos empreendedores por gênero pode ser observada no Gráfico 4:

Gráfıco 4: distribuição do perfil de empreendedores por gênero.

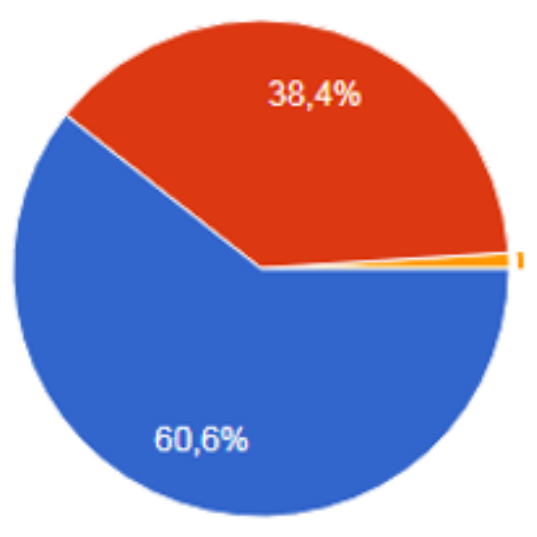

Feminino

Masculino

Prefiro não dizer

Fonte: dados da pesquisa (2019).

INSCREVA-SE

\section{Os seus sonhos} não podem esperar
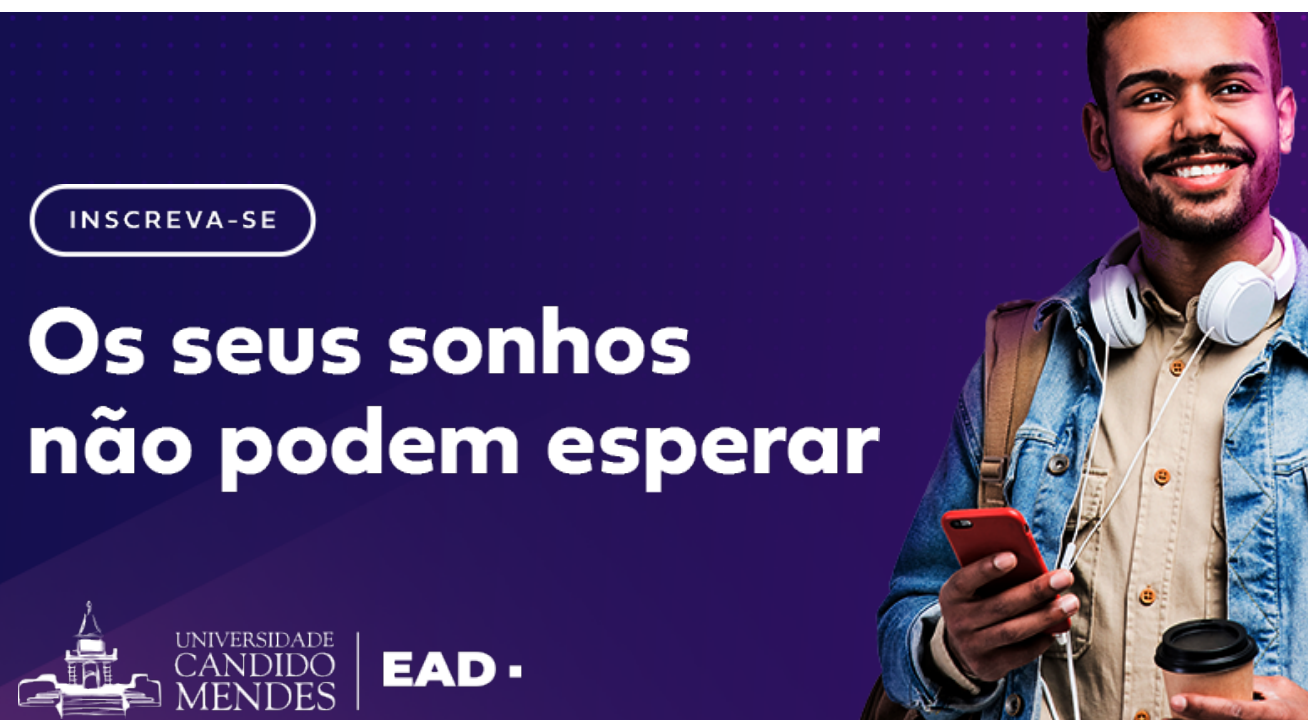
As mulheres são maioria entre os microempreendedores. 0 número de empresários do gênero feminino supera os $60 \%$ do total, enquanto os empresários do gênero masculino e os que optaram por não dizer somam juntos apenas $39.4 \%$ do total. Tal fato é interessante, dado que pode representar o empoderamento feminino e uma maior representatividade em atividades empreendedoras no município.

Quanto à idade há um equilíbrio entre os intervalos de 21 a 30 anos (22,2\%), de 31 a 40 anos (30,3\%), de 41 a 50 anos $(19,2 \%)$ e empresários com mais de 50 anos $(28,3 \%)$, não sendo possível notar grandes discrepâncias. É válido ressaltar que, entre os entrevistados, não houve nenhum tomador de crédito com menos de 20 anos.

É possível observar grande variação da amostra quanto ao grau de instrução dos tomadores de crédito. 0 Gráfico 5 apresenta a distribuição deles de acordo com a instrução:

Gráfico 5: distribuição da amostra conforme grau de instrução.

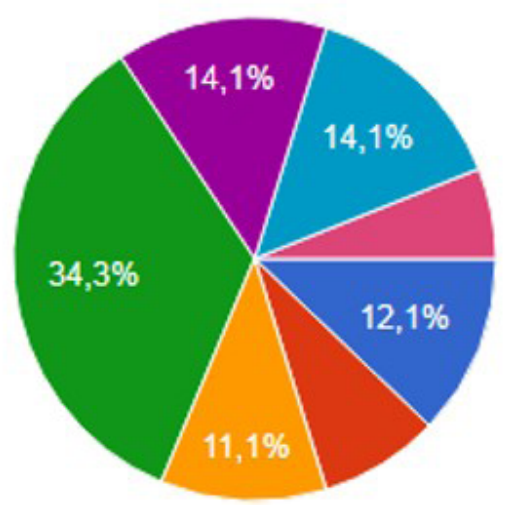

I grau incompleto

I grau completo

- II grau incompleto

- II grau completo

- III grau incompleto

- III grau completo

Pós graduação

Fonte: dados da pesquisa (2019).

\section{A QUALIDADE DE ENSINO QUE VOCE JÁ CONHECE.}

INSCREVA-SE

\section{AGORA!}

口 PRESENCIAL

口 SEMIPRESENCIAL

口 EAD 
Sobre o grau de instrução dos tomadores de crédito, os empresários com segundo grau completo são destaque, fazendo com que os que possuem primeiro grau incompleto, primeiro grau completo, segundo grau incompleto, terceiro grau completo e pós-graduação estejam quase em equilíbrio até o momento da pesquisa de campo.

Do total de entrevistados, apenas 37,9\% dos microempreendedores alegaram ter algum curso de formação na área de atuação da empresa. Os outros $62,1 \%$ não possuem cursos de formação. Entre os 37,9\% dos empresários citados, grande parte alega ter feito cursos de formação através de parcerias entre o município e o SEBRAE.
No que se refere à forma de conhecimento do programa de concessão de crédito, o Gráfico 6 apresenta as possíveis formas pelas quais os empreendedores tomaram conhecimento do programa.

Gráfico 6: distribuição das formas de acesso ao programa.
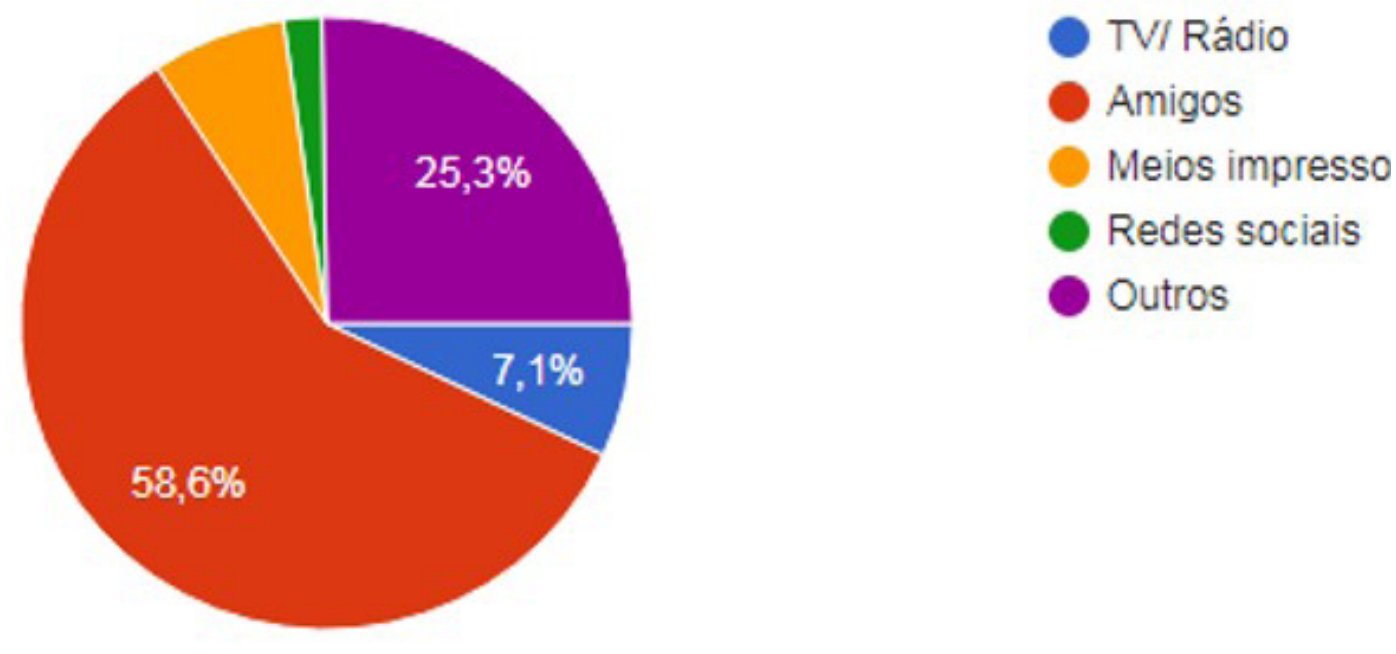

Fonte: dados da pesquisa (2019).

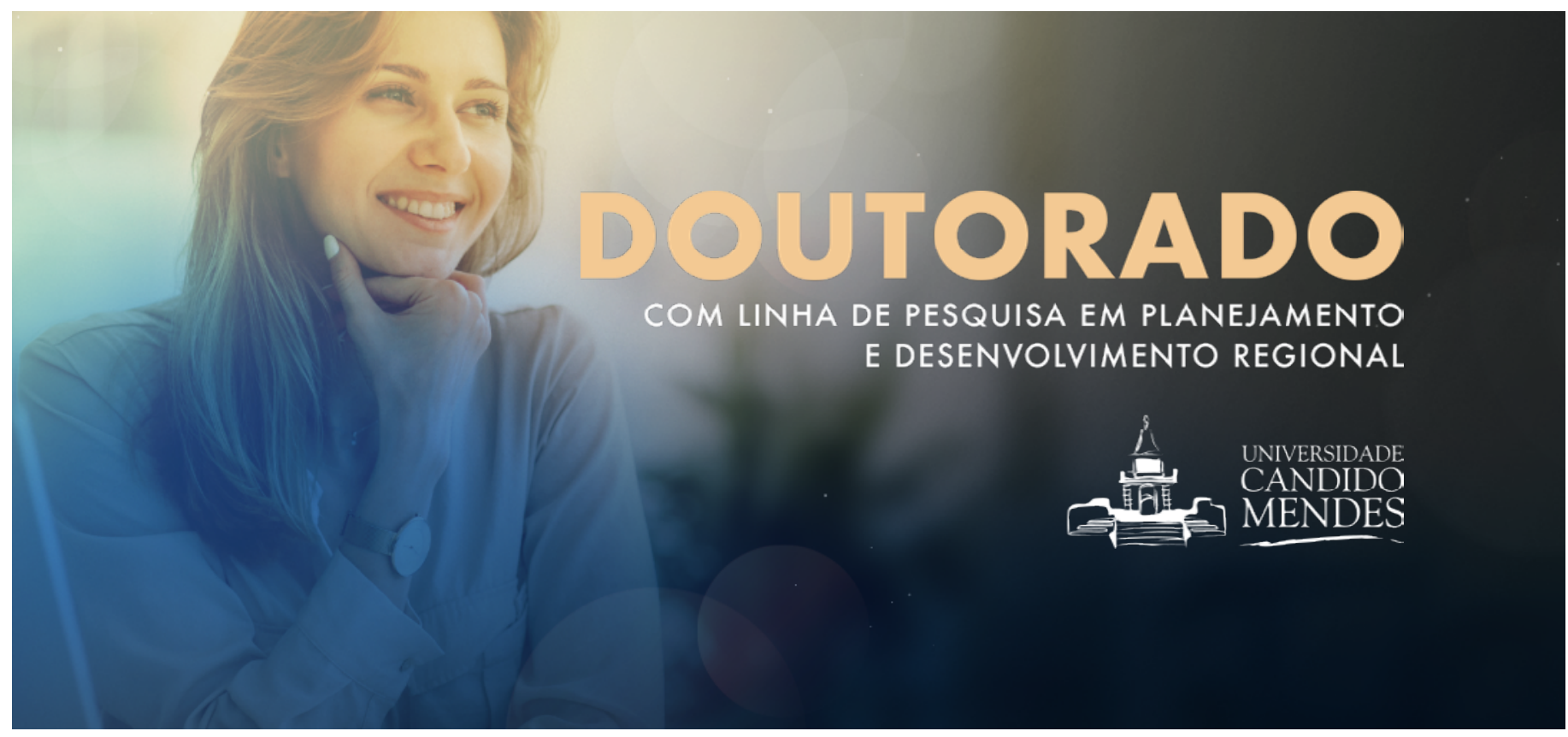


Apesar de existirem divulgações em canais oficiais da prefeitura sobre as linhas de crédito do Fundecam na TV/ Rádio, redes sociais e por meios impressos, a maior parte dos tomadores de crédito do Fundecam Empreendedor ficou sabendo do programa por amigos e outros meios.

Nos outros meios, grande destaque deve ser dado ao Espaço da Oportunidade, da Secretaria de Desenvolvimento Econômico do Município de Campos, que, ao realizar o cadastro de pessoas jurídicas, indica o Fundecam como alternativa.
A análise dos resultados dos negócios dos tomadores de crédito no que tange a vendas, contratação, mão de obra e vendas pode ser observada no Gráfico 7 :

Gráfico 7: resultados das empresas após a tomada de crédito.

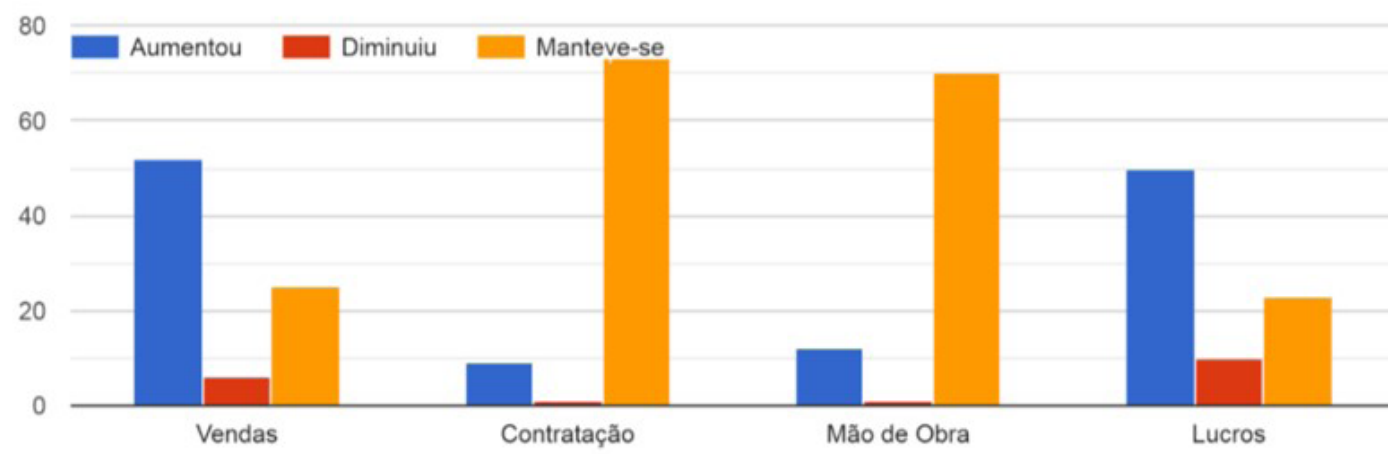

Fonte: dados da pesquisa (2019).

MES T R A D 0

PESQUISA OPERACIONAL E INTELIGÊNCIA COMPUTACIONAL

LINHA DE PESQUISA EM SAÚDE

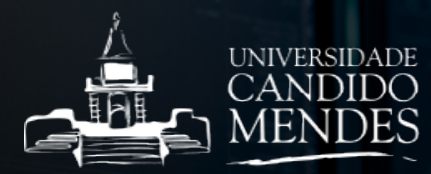


Analisando o efeito da aplicação dos recursos nos negócios, segundo os microempreendedores, apesar de no geral não haver aumento no número de contratações e de mão de obra, houve um significativo aumento nas vendas e, por consequência, nos lucros das empresas. Ocupando-se dos lucros, $50 \%$ dos empresários alegaram que aumentaram; 23\% apontaram a conservação da situação anterior; e meramente 10\% dos tomadores de crédito perceberam algum declínio nos lucros.

No que tange à pontualidade dos pagamentos, até 0 momento da aplicação dos questionários, o pagamento das parcelas em dia estava seguindo a proporção 9:1 entre os clientes do Fundecam Empreendedor, representando baixo nível de inadimplência intrínseca ao programa.

Por fim, 57,6\% dos empreendedores classificaram 0 Programa Fundecam Empreendedor como muito bom, e destacaram o acompanhamento dos consultores do negócio como elemento de alavancagem. Do total de empreendedores, $36,4 \%$ consideraram o programa como regular; $5,1 \%$, como bom; e 1\%, como ruim.

Os empresários que alegaram não terem avaliado o programa como "muito bom" acharam o valor dos créditos muito baixos.

Este resultado aponta para um bom desempenho do Programa Fundecam Empreendedor, impactando os microempreendedores locais e contribuindo para o desenvolvimento regional endógeno.

\section{Considerações finais}

A partir deste estudo, foi possível identificar o perfil dos tomadores de microcrédito no Programa Fundecam Empreendedor em Campos dos Goytacazes, interior do estado do Rio de Janeiro.

Para o desenvolvimento de ações de planejamento e de retroalimentação do programa, é importante a identificação do perfil dos tomadores de microcrédito e a análise da alocação dos recursos em seus negócios possibilitando sua ampliação e sua contribuição para o desenvolvimento regional.

A verificação da ampliação dos valores de crédito concedidos, juntamente com o acompanhamento dos consultores empresariais, pode ser uma forma de ampliar o desenvolvimento regional endógeno. Enquanto as pesquisas de campo ainda estavam em curso, o Fundecam dobrou 0 valor limite das concessões de crédito de todas as linhas, como foi publicado no site oficial da Prefeitura de Campos no dia 11 de fevereiro de 2019. Trata-se da integração das ações de governo, empresa e sociedade gerando benefícios mútuos para o município.

0 desenvolvimento regional endógeno depende da consonância entre as ações de três atores: o público, o privado e a sociedade civil organizada. Todos esses atores têm 0 papel de estimular ou dar condições que permitam o crescimento e o desenvolvimento em prol dos objetivos locais. 


\section{Referências}

ABDALA, V. Taxa de desemprego cresce para 12,6 \% em abril, diz IBGE. Empresa Brasil de Comunicação (EBC), 28/05/2020. Disponível em: https:// agenciabrasil.ebc.com.br/economia/noticia/2020-05/taxa-de-desemprego-cresce-para-126-em-abril-diz-ibge. Acesso em: 24 jun. 2020

AMARAL FILHO, J. do. Desenvolvimento regional endógeno em um ambiente federalista. Revista Planejamento e Políticas Públicas, Rio de Janeiro IPEA, n. 14 , p. $37-38$, dez. 1996

BARBOZA, Ricardo de Menezes and ZILBERMAN, Eduardo. Os Efeitos da Incerteza sobre a Atividade Econômica no Brasil. Rev. Bras. Econ. [online] v. 72, n. 2, p. 144-160, 2018. https://doi.org/10.5935/0034-7140.20180007. Acesso em : 27 maio 2019.

BARQUERO, A. V. Desenvolvimento Endógeno. In: BARQUERO, A. V. Desenvolvimento endógeno em tempos de globalização. Tradução de Ricardo Brinco.Porto Alegre: Fundação de Economia e Estatística, 2001.

BARONE, P. M.; PAULO, F. L.; DANTAS, V.; REZENDE, V. Introdução ao Microcrédito. Brasília: Conselho da Comunidade Solidária. 2002.

BRAGA, T. M. Desenvolvimento Local Endógeno entre a competitividade e a cidadania.: R. B. Estudos Urbanos e Regionais, Rio de Janeiro, n. 5, 2002. Disponível em: http://rbeur.anpur.org.br/rbeur/article/view/63/47. Acesso em: 10 nov. 2019.

BRESSER-PEREIRA, L. C. Estratégia Nacional e Desenvolvimento. Revista de Economia Política, v. 26, n. 2, p. 203-230, abr./jun. 2006.

CAMPOS. Lei $\mathbf{n}^{\mathbf{0}} \mathbf{8 1 4 2}$, de $\mathbf{2 9}$ de dezembro de $\mathbf{2 0 0 9}$. Dispõe sobre a criação da linha especial de financiamento, direcionado para a implantação do microcrédito no município de Campos dos Goytacazes e dá outras providências. Disponível em: https://leismunicipais.com.br/a/rj/c/campos-dos-goytacazes/lei-ordinaria/2009/814/8142/lei-ordinaria-n-8142-2009-dispoe-sobre-a-criacao-de-linha-especial-de-financiamento-direcionado-para-implantacao-do-microcredito-no-municipio-de-campos-dos-goytacazes-e-da-outras-providencias. Acesso em: 25 agosto 2019.

LESSA, D. Um alento para os sem-crédito. Revista Rumos, Rio de Janeiro. p. 40, abr. 2001.

ROMER, P. M, The Origins of Endogenous Growth. E.U.A. Journal of Economic Perspectives, v. 8, n. 1, p. 3-22, Winter, 1994.

SCHUMPETER, J. A Teoria do Desenvolvimento Econômico. São Paulo: Abril Cultural, 1982.

SEBRAE (org.) Anuário do trabalho na micro e pequena empresa: 2007. Serviço Brasileiro de Apoio às Micro e Pequenas Empresas; Departamento Intersindical de Estatística e Estudos Socioeconômicos [responsável pela elaboração da pesquisa, dos textos, tabelas e gráficos]. Brasília, DF : DIEESE, 2007.

OLIVEIRA, A. B. S. Métodos e técnicas de pesquisa em contabilidade. São Paulo: Saraiva, 2003.

OLIVEIRA, M. A. de. A Importância estratégica e econômica da instalação de uma fábrica de Circuitos Integrados no Brasil. Biblioteca pública virtual de Belo Horizonte, p. 71, 2003. Disponível em: http: // www. Ip.pbh.gov.br/ANOS5_n2_PDF/ip0502aparecido.pdf. Acesso em: 10 set. 2018.

PEREIRA, J. A ; SOUZA, L. H. Empreendedorismo e Microcrédito produtivo e orientado: um estudo sobre o programa crescer. Gestão \& Planejamento, UNIFACS, Salvador. v. 18, p. 119-139, jan. 2017. Disponível em: https://revistas.unifacs.br/index.php/rgb/article/view/3487. Acesso em: 12 abr. 2018.

SOUZA FILHO, J. R. Desenvolvimento Regional Endógeno, Capital Social e Cooperação, Porto Alegre: UFRGS, 1999. Disponível em: http://www.yorku.ca/ishd/LEDCD.SP/Links\%20BQ/68_Desenvolvimento_regional_endogeno_capital_social_coopera.pdf. Acesso em: 06 maio 2018.

TOMELIN, M. 0 Microcrédito no Brasil. 2003. Disponível em: https://pt.scribd.com/document/93779149/ 0-Microcredito-No-Brasil. Acesso em: 08 mar. 2019.

YUNUS, M.; JOLIS, A. 0 banqueiro dos pobres. São Paulo: Ática, 2006. 